\title{
Myeloid Sarcoma of the Orbit Preceding Acute Myeloid Leukaemia: A Diagnostic Challenge
}

Oluomachi Charity Nnachi ${ }^{1}$, Robert Azu Nnachi ${ }^{2}$, Innocent Paul Ezenwenyi ${ }^{1}$, Ogah Emeka Onwe ${ }^{3}$, Augustine Ejike Okoye $^{1}$, Chukwuemeka Okorie Eze ${ }^{4}$, Matilda Adesuwa Ojo ${ }^{5}$, Ugochukwu Uzodinma Nnadozie ${ }^{6}$, Edak Ezeanosike $^{7}$ \& Joseph Chukwuma Uzoigwe ${ }^{8}$

${ }^{1}$ Department of Haematology and Blood Transfusion, Alex Ekwueme Federal University Teaching Hospital Abakaliki, Ebonyi State, Nigeria

${ }^{2}$ Deparmtment of Accountancy/Banking and Finance, Faculty of Management and Social Sciences, Alex Ekwueme Federal University Ikwo, Ebonyi State, Nigeria

${ }^{3}$ Department of Paediatrics, Alex Ekwueme Federal University Teaching Hospital, Abakaliki, Ebonyi State, hNigeria

${ }^{4}$ Department of Internal Medicine, Alex Ekwueme Federal University Teaching Hospital Abakaliki, Ebonyi State, Nigeria

${ }^{5}$ Department of Haematology and Immunology, University of Medical Sciences, Ondo State, Nigeria

${ }^{6}$ Division of Plastic Surgery, Department of Surgery, Alex Ekwueme Federal University Teaching Hospital Abakaliki, Ebonyi State, Nigeria

${ }^{7}$ Department of Ophthalmology, Alex Ekwueme Federal University Teaching Hospital, Abakaliki, Ebonyi State, Nigeria

${ }^{8}$ Department of Morbid Anatomy, Alex Ekwueme Federal University Teaching Hospital Abakaliki, Ebonyi State, Nigeria

Correspondence: Oluomachi Charity Nnachi, Department of Haematology and Blood Transfusion, Alex Ekwueme Federal University Teaching Hospital Abakaliki, Ebonyi State, Nigeria. Tel: 234-803-544-2642. E-mail: ranex2x@gmail.com.

Received: October 20, 2019 Accepted: December 2, 2019 Online Published: December 12, 2019

doi:10.5539/gjhs.v11n14p98 URL: https://doi.org/10.5539/gjhs.v11n14p98

\begin{abstract}
Objective: Myeloid sarcoma is a rare form of acute myeloid leukaemia characterized by extramedullary proliferation of myeloid blasts which can occur as an isolated lesion in any organ. Even rarer it may occur in the orbit as the initial presentation without a leukaemic phase and diagnosis may be challenging when it is not suspected.
\end{abstract}

Methods: We report a case of orbital myeloid sarcoma as the initial presentation of acute myeloid leukaemia in an adult who was misdiagnosed and treated as a case of a pseudotumour with resultant significant disease progression and worsening of the clinical condition. There was a lag of four months from the onset of eye mass to the development of acute myeloid leukaemia.

Result: Due to patients worsening condition and tumour progression, a repeat biopsy for a second histology opinion at a different facility, immunophenotyping and immunohistochemistry were employed to arrive at the correct diagnosis. Following chemotherapy, the orbital mass reduced markedly and clinical condition improved. The patient was indigent and could not sustain further funding of his treatment because he had already spent much on for management of complications he developed before a definitive diagnosis could be made.

Conclusion: Myeloid sarcoma can present as an orbital mass without a leukemic disease. Therefore a high index of suspicion, meticulous examination of biopsy, immunohistochemistry and collaboration between oncologists and ophthalmologists, are required to arrive at an early accurate diagnosis.

Keywords: Acute Myeloid Leukaemia, Myeloid Sarcoma, Diagnostic Challenge 


\section{Introduction}

Acute myeloid leukaemia (AML) is a heterogeneous group of diseases characterized by uncontrolled proliferation of myeloid progenitor cells that gradually replace normal haematopoiesis in the bone marrow. AML accounts for about $15 \%-20 \%$ of acute leukaemias in children and adolescents and $80 \%$ in adults (Kouchkovsky \& Abdul-Hay, 2016).

A unique but rare $(<1 \%)$ form of AML called myeloid sarcoma (MS) is a clinical situation in which a tumour-like proliferation of myeloid blasts occurs outside the bone marrow (Dores, Devesa, Curtis, Linet, \& Morton, 2012). These tumour masses of myeloid blasts disrupt the tissue architecture unlike AML with tissue infiltrates where the underlying architecture is preserved (Wang \& Li, 2016). MS occurs most in M5a (monoblastic), M5b (monocytic), M4 (myelomonocytic) AML subtypes (Byrd, Edenfield, Shields, \& Dawson, 1995).

MS can occur in virtually any organ or tissue. This includes connective and soft tissues, skin, breast, digestive system, lymph nodes, orbit of the eyes, uterus, mediastinum (Goyal, Bartley, Patnaik, Litzow, AI-Kali, \& Go, 2017; Audouin, Comperat, Le Tourneau, Camilleri-Broet, Adida, Molina, Diedold, 2003; Seifert, Bulkeley, Zhang, Menes, \& Bui, 2014). However ophthalmic manifestations have been reported to be rare (Kincaid \& Green, 1983; Schachat, 1989).

MS can occur in diverse clinical presentations including; (Christopher, William, \& Bonnie, Seong-Jin, Farahvar, Chen, \& Wang, 2014; Dock, 1983).

a) Initial presentation in a healthy individual in whom a typical AML with leukaemic phase evolves after an interval of weeks, months or years

b) The first manifestation of relapse in a patient previously treated for leukaemia

c) Patients in the active phase of AML

MS occurs in all age groups with some reports showing a median age of 56 years and a wide range of 1 month to 89 years (Falini et al., 2007; Piled et al., 2007; Neiman, Barcos, Berard, Bonner, Mann, Rydell, \& Bennett, 1981; Goyal et al., 2017). Males are more affected than females (Goyal et al., 2017) while distribution by race shows more whites affected than blacks but overall survival worse in blacks (Goyal et al., 2017).

MS when presenting as the initial feature of AML can be a diagnostic dilemma (Vardiman et al., 2009; Kiratli, Balci, Himmetoglu, \&Uner, 2009; Mangla, Dewan, \& Meyer, 2012; Balyen, DenizBalyen, \&Pasa, 2016) more so when it occurs in rare sites including the orbit as presented in this case report.

\section{Case Summary}

A case of a nineteen year (19yr) old Nigerian male student who presented with four (4) months history of protrusion of both eyes worse on the right. See Figure 1. This was gradual in onset but progressive. There were associated gradual loss of vision, pain (throbbing), that radiates to the frontal area of the head, generalized headache, occasional dizziness, vomiting, catarrh and hearing loss on the right ear. There was no history of fever, weakness, bone pain, night sweats, chest pain nor cough.

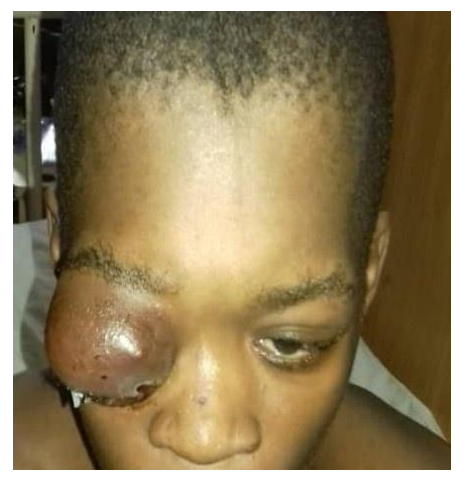

Figure 1. Facial Photograph at first presentation shows proptosis of both eyes worse on the right 


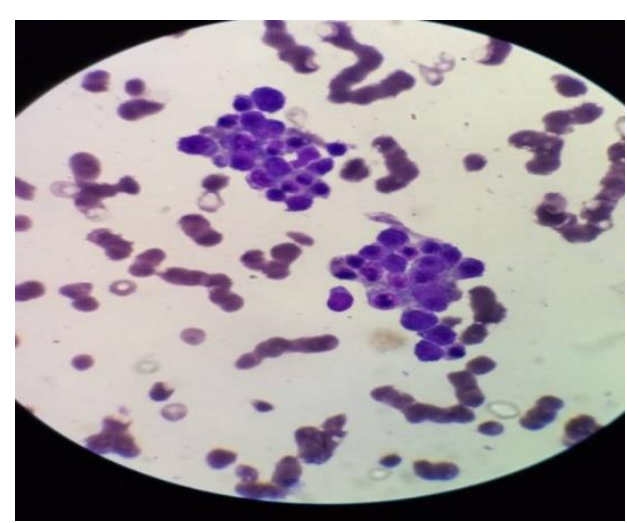

Figure 2. Bone Marrow Picture at First Presentation. Shows Erythorid Clusters And Reduction in Other Cell Lines

Examination revealed a young male, not in any obvious distress, with bilateral protrusion of the eyes (worse on the right eye), afebrile, moderately pale, anicteric, acyanosed, not dehydrated, no palpable lymph node enlargement and no pedal oedema. The eye mass was fleshy red with dry crusty blood clot covering some areas. An incisional biopsy was planned to aid diagnosis and workup laboratory and radiological tests were done. Initial full blood count (FBC) revealed moderate anaemia, thrombocytopenia and neutropenia. These were corroborated by a peripheral blood film report and Bone Marrow Aspiration showed depression of myeloid and megakaryocytic cell lines, erythroid clusters, no foreign cells. See Figure 2.Histology report gave a diagnosis of idiopathic orbital inflammatory disease (pseudotumour) with dense lymphocytic infiltrates.

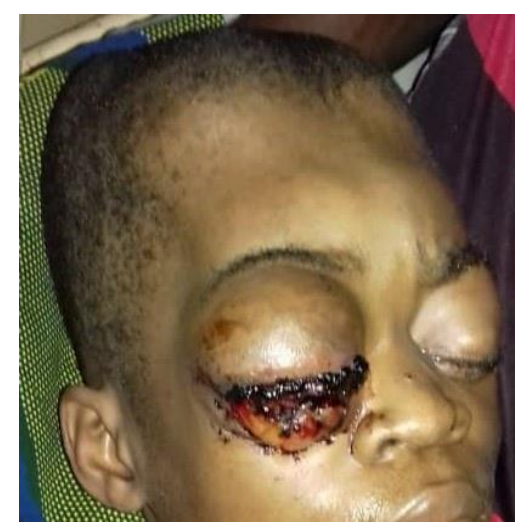

Figure 3. Facial Photograph shows an increase in orbital mass and development of multiple masses on the scalp

Orbital CT scan revealed a homogenous mass in each orbit. The right mass measured $49 \times 32 \times 10 \mathrm{~mm}$ while the left was $26 \times 11 \times 10 \mathrm{~mm}$. A radiological diagnosis of bilateral proptosis secondary to orbital mass was made.

Based on the histology report, he was admitted and immediately commenced on oral and topical antibiotics, tear substitutes to prevent desiccation of the exposed eyeball, and steroids. He was then placed on IV methylprednisolone for 3 days and later maintained on tablet prednisolone for eleven days; oral calcium gluconate $100 \mathrm{mg}$ daily for two (2) weeks. While on this therapy, his vision on the left eye improved a bit but subsequently his clinical condition deteriorated four months later on follow-up visit. He was found to be febrile (high-grade fever), severely pale and weak. Eye protrusion worsened with associated haemorrhage, loss of sight in the right eye and hearing loss in the right ear. He also developed multiple scalp swellings. See figure 3 . This then necessitated a review of his initial diagnosis.

A repeat biopsy for a second opinion was ordered. Pre-surgery FBC then showed severe thrombocytopaenia of 30,000 per microlitre and White Cell Count of 103,000 per microlitre with Absolute Neutrophil Count of 96,000 per microlitre. Peripheral Blood Film showed neutrophilia with monoblasts and myeloblasts.

The orbital tumour was biopsied again for a repeat histology diagnosis at a different facility to get a second opinion. The histology report showed malignant myeloid proliferation made up of extensive sheets of primitive blasts. 
Intermediate-sized cells with rounded vesicular nuclei with prominent nucleoli and scanty cytoplasm with some occasional cells having brightly eosinophilic granular cytoplasm were seen and were suggestive of granulocytic sarcoma. Immunohistochemistry was requested. The result of immunohistochemistry sowed a high positivity for CD14 confirming that it is myeloid sarcoma of the monoblastic variant.

Consequently, he was then worked up for chemotherapy following counselling and informed consent. He was transfused with 3 units of packed red cells and an adult unit of platelet concentrates before chemotherapy. He had DA (Doxorubicin $25 \mathrm{mg} / \mathrm{m}^{2}$ for 3 days and Ara $-\mathrm{C} 100 \mathrm{mg} / \mathrm{m}^{2}$ for one week. While on chemotherapy he had adequate blood support. After the first induction had been completed he had achieved a complete remission with the disappearance of the scalp swellings and gross reduction of the orbital tumour ( $>80 \%$ reduction). See figure 4 and 5. He was then scheduled for a second induction therapy but due to financial constraints, he could not procure the chemotherapy drugs and blood product support. Subsequently, his clinical condition deteriorated and he developed multiple organ failure and later succumbed to death.

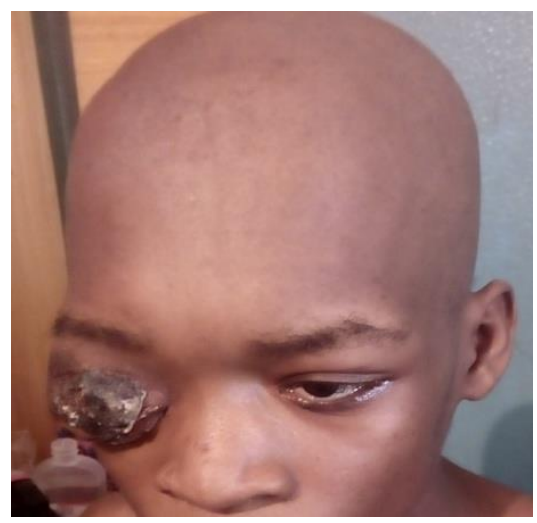

Figure 4. Facial Photograph shows marked reduction of orbital mass and disappearance of scalp swellings two weeks later after receiving induction chemotherapy

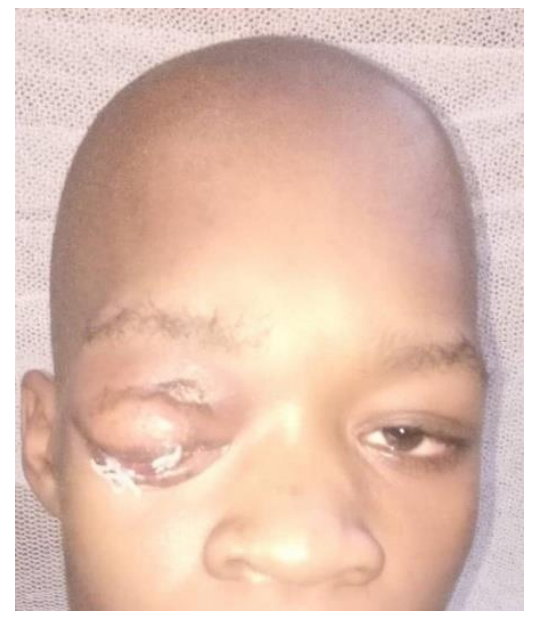

Figure 5. Facial Photograph shows more than $90 \%$ reduction of orbital mass four weeks after induction chemotherapy. However right eye orbit was destroyed

\section{Discussion}

Myeloid sarcomas are discrete tumours of leukaemic myeloblasts or occasionally leukaemic monocytes. They develop in the skin and soft tissues, periosteum, and bone, lymph nodes, gastrointestinal tract, pleura, gonads, urinary tract, central nervous system and other sites including the orbit. Orbital MS is quite uncommon in adults unlike in children where it relatively occurs (Shields, Stopyra, Marr, Shields, Pan, Eagle Jr, \& Bernstein, 2003; Diand, Yadav, Grover, Bhalla, \& Sachdav, 2013). MS may be the first manifestation of AML preceding the onset in marrow and blood by months or years (Christopher et al., 2014; Dock, 1983; Max, A. L., Charalampakis, Ford, Gourevitch, \& Desai, 2017). Our patient who presented initially with an orbital sarcoma developed systemic 
manifestation of AML in the bone marrow and peripheral blood after eight months from onset of eye swelling. Studies have shown that the median time to develop AML from extramedullary MS range from 5months to 12 months (Goyal et al., 2017). Our patient presented initially without bone marrow and peripheral blood disease as evidenced by the report of bone marrow biopsy and peripheral blood film (see Figure 3). The cytopenias he had was then attributed to an eye tumour with probable bone marrow suppression.

Definitive diagnosis with histology is pivotal to commencement of appropriate therapy and MS is often misdiagnosed (Alexier, Wang, Ning, Chumsri, Gojo, Rodgers, Stass, \& Zhao, 2007). The initial histological diagnosis of pseudotumour, in this case, could have been mistakenly informed by the cellular infiltrates thought to be lymphoid and the low index of suspicion of the clinicians (Menasce, Banerjee, Bcekett, \& Harris, 1999). Moreover, pseudotumor accounts for a majority of painful orbital mass in adults (Ding, Lip, \& Chong, 2011). MS has also been commonly misdiagnosed as non-Hodgkin's lymphoma, small round cell tumour and undifferentiated carcinoma when histology is used alone (Alexier et al., 2007). The diagnosis of orbital MS is usually hinged on histology which was missed in our case and subsequent treatment of the patient with steroid therapy lead to initial mild improvement of vision in the left eye and development of more masses on the scalp and inner ear with hearing loss and worsening of patient's clinical condition.

Due to further deterioration of patient's clinical condition, a repeat histology of the orbital tumour biopsy was done and more definitively immunohistochemistry was performed, while immunophenotyping was done with the peripheral blood and repeat bone marrow aspirate which now showed involvement by the leukaemic cells. The histologic features of MS are similar to those of myeloid blasts of the various subtypes of AML. Microscopically there is a diffuse homogenous medium to large blastic with ovoid nuclei and centrally located nuclei with open chromatin, scanty to moderate cytoplasm and high mitotic count (Alexier et al., 2007). This is typical of what was seen in this index case on repeat histology.

A definitive diagnosis of MS is based on immunohistochemistry (Brunning, Bennett, Flandrin, Matutes, Varidman, \& Harris, 2001; Chang, Eshoa, Kampalath, Shidham, \& Perkins, 2000). Fresh tissue specimens may also be analyzed by flow cytometric analysis. MS also have immunophenotypic features identical to AML. Immunohistochemical stains used include CD3+, CD117) which are positive in undifferentiated blasts (B7) and also markers to establish myeloid or monocytic differentiation (myeloperoxidase [MPO] CD68 - R EPGMI clone) lysozyme, CD83, CD14, CD 163 etc.). Immunohistochemical stain of our patient's biopsy sample showed CD33 (weak) <24\% CD 14 (strong) 66\% which is suggestive of a monocytic subtype.

Myeloid sarcomas are associated with some chromosomal abnormalities including $\mathrm{t}(8 ; 21)(\mathrm{q} 22 ; \mathrm{q} 22)$, trisomy;11, trisomy 8 etc (Piled et al., 2007; Chakraborty, Adams, Nassiri, \& Vance, 2014; Schwyzer, Sherman, Cohn, Poole, $\&$ Willem, 1998).

Following diagnosis (which was made late due to initial misdiagnosis) patient could not be started on full definitive treatment immediately because his general condition was bad due to disease advancement. He was resuscitated with blood support, oxygen therapy, fluid and antibiotics before definitive treatment with chemotherapy. Treatment of MS is same with AML where chemotherapeutic regimen courses are instituted (Bakst, Tallman, Douer, \& Yahalom, 2011; Al-Khateed, Bdheed, Haddad, Marei, \& Abbasi, 2011; Stepensky, Revel-Vilk, Yehuda-Gafni, Mali, Resnick, \& Weintraub, 2009). Debulking surgeries can also be employed (Bakst et al., 2011; Ooi, Chim, Khong, Au, Lie, Tsang, \& Kwong, 2001; Imrie et al., 1995). Due to financial constraints, our case received only induction therapy with doxorubicin and cytarabine and had a very good clinical response (see Figures $4 \& 5$ ). Treatment could not continue due to financial reasons. Patient was indigent and had spent so much in the management of complications he developed before accurate diagnosis could was made. Overall survival and prognosis is variable and depends on several factors including sites affected, race, age and sex (Edgerton, 1947; Balyen et al., 2016). Though debatable, it is predicted that a patient with MS with leukaemic features portends a poor clinical outcome and shorter survival (Balyen et al., 2016). The overall survival of those with extramedullary myeloid sarcoma appears to vary significantly based on the patient's age, sex, race and sites of presentation. Our patient's early death due to the inability to procure blood support needed to complete his chemotherapy doses could not allow us to conclude on the long-term clinical outcome.

MS involving the orbit is a big masquerader and diagnosis can be challenging for clinicians and histopathologists as seen in the case presented. When evaluating a patient with orbital mass, the ophthalmologist, in collaboration with other specialists (including pathologists) should consider a wide variety of benign and malignant conditions, employ appropriate investigations with the aim of reaching an accurate diagnosis that will facilitate the early institution of definitive management. This will greatly improve patient outcome without depleting patients' scarce funds unduly and worsening of clinical status before definitive treatment is instituted as was in our patient's case. 


\section{Declaration of Patient Consent}

The authors certify that they have obtained all appropriate patient consent forms. The patient has given his consent for his image and other clinical information to be reported in the journal. The patient understands that his identity will be concealed.

\section{Competing Interests Statement}

The authors declare that there are no competing or potential conflicts of interest.

\section{References}

Alexier, B. A., Wang, W., Ning, Y., Chumsri, S., Gojo, I., Rodgers, W. H., Stass, S. A., \& Zhao, X. F. (2007).Myeloid Sarcomas: A Histologic, Immunohistochemical, and Cytogenetic Study. Diagnpathol, 2(42). https://doi.org/10.1186/1746-1596-2-42

Al-Khateed, H., Bdheed, A., Haddad, H., Marei, L., \& Abbasi, S. (2011). Myeloid Sarcoma: Clinic Pathologic, Cytogenetic, and Outcome Analysis of 21 Adult Patents. Leukemia Research and Treatment, 2011, 523168. https://doi.org/10.4061/2011/523168

Audouin, J., Comperat, E., Le Tourneau, A., Camilleri-Broet, S., Adida, C., Molina, T., \& Diedold, J. (2003). Myeloid Sarcoma: Clinical and Morphologic Criteria useful for Diagnosis. International Journal Surge Pathol, 11(4), 271-282. https://doi.org/10.1177/106689690301100404

Bakst, R. L., Tallman, M. S., Douer, D., \& Yahalom, J. (2011). How I treat Extramedullary Acute Myeloid Leukemia. Blood, 118(14), 3785-3793. https://doi.org/10.1182/blood-2011-04-347229

Balyen, L., DenizBalyen, L. S., \& Pasa, S. (2016). A Case of Orbital Granulocytic Sarcoma ChloroiOphthalmol. Vis Syst, 5(1), 00139. https://doi.org/10.15406/aovs.2016.05.00139

Brunning, R. D., Bennett, J., Flandrin, G., Matutes, E., Varidman, J. W., \& Harris, N. A. (2001). Acute Myeloid Leukemia not otherwise categorized in: Jaffe, E. S., Harris, N. L., and stein, H., and Vardiman, J. W., (Eds.), WHO Classification of Tumours; Pathology and Genetics of Tumours of Hematopoietic and Lymphoid Tissues. Lyon: IARC Press

Byrd, J. C., Edenfield, J., Shields, D. J., \& Dawson, N. A. (1995). Extramedullary myeloid Cell Tumors in Acute Nonlymphocytic Leukemia: A Clinical Review. Journal of ClinOncol, 131800-1816. https://doi.org/10.1200/JCO.1995.13.7.1800

Chakraborty, S., Adams, J., Nassiri, M., \& Vance, G. H. (2014). Therapy-related myeloid neoplasm with bone marrow involvement, myelosarcoma, and a $\mathrm{t}(8 ; 16)(\mathrm{p} 11.2 ;$ p13.3)-a case report. Cancer Genet, 207(10-12), 511-515. https://doi.org/10.1016/j.cancergen.2014.10.008

Chang, C. C., Eshoa, C., Kampalath, B., Shidham, V. B., \& Perkins, S. (2000). Immunophenotypic Profile of Myeloid Cells in Granulocytic by Immunohistochemistry. Correlation with Blast Differentiation In Bone Marrow. Am J Clin Pathol, 114, 807-811. https://doi.org/10.1309/WWW7-DG6X-HC16-D7J2

Christopher, P., William, C. O., Bonnie, W., Seong-Jin, M., Farahvar, A., Chen, E., \& Wang, H. (2014). Myeloid Sarcoma: A Rare Case of an Orbital Mass Minnicking Orbital Psendotumour Requiring Neurosurgical Intervention. Case Reports In Neurological Medicine. https://doi.org/10.1155/2014/395196

Diand, V., Yadav, S. P., Grover, A. K., Bhalla, \& Sachdav, A. (2013). Orbital Myeloid Sarcoma Presenting as Massive Proptosis.Hematology Oncology and Stem Cell Therapy, 6(1), 26-28. https://doi.org/10.1016/j.hemonc.2013.02.005

Ding, Z. X., Lip, G., \& Chong, V. (2011). Idiopathic orbital pseudotumour. Clinical Radiology, 66(9) 886-892. https://doi.org/10.1016/j.crad.2011.03.018

Dock, G. (1983). Chloroma and its Relationship to Leukemia. Am J Med sci., 106, 152-167. https://doi.org/10.1097/00000441-189308000-00003

Dores, G. M., Devesa, S. S., Curtis, R. E., Linet, M. S., \& Morton, L. M. (2012). Acute Leukemia and Patient Survival among Children and Adults in the United States, 2001-2007. Blood, 199, 34-43. https://doi.org/10.1182/blood-2011-04-347872

Edgerton, A. E. (1947). Chloroma: Report of a Case and Review of the Literature. Trans Am ophthalolsoc, 45, 376.

Falini, B., Lenze, D., Hasserjian, R., Coupland, S., Jaehne, D., Soupir, C., ... Stein, H. (2007). Cytoplasmic Mutated Nucleophosmin (NPM) Defines the Molecular Status of a Significant Fraction of Myeloid Sarcomas. 
Leukemia, 21(7),1566-1570. https://doi.org/10.1038/sj.leu.2404699

Goyal, G., Bartley, A., Patnaik, M., Litzow, M. R., AI-Kali, A., \& Go, R. S. (2017). Clinical Features and Outcomes of Extramedullary Myeloid Sarcoma in the United States: Analysis using a National Data Set. Blood Cancer Journal, 7(8), 592. https://doi.org/10.1038/bcj.2017.79

Imrie, K. R., Kovacs, M. J., Selby, D., Lipton, J., Patterson, B. J., Pantalony, D., Poldre, P., Bo-Yee, N., \& Keating, A. (1995). Isolated Chloroma: The Effect of Early Antileukemic Therapy. Annals of Internal Medicine, 123. https://doi.org/10.7326/0003-4819-123-5-199509010-00005

Shields, J. A., Stopyra, G. A., Marr, B. P., Shields, C. L., Pan, W., Eagle Jr, R. C., \& Bernstein, J. (2003). Bilateral Orbital Myeloid Sarcoma as Initial Sign of Acute Myeloid Leukemia: Case Report and Review of the Literature. Arch Ophthalmol, 121(1), 138. https://doi.org/10.1001/archopht.121.1.138

Kincaid, M. C., \& Green, W. R (1983). Ocular and Orbital involvement in Leukemia. SurvOphthalmol, 27, 211-232. https://doi.org/10.1016/0039-6257(83)90123-6

Kiratli, H., Balci, K. E., Himmetoglu, C., \& Uner, A. (2009). Isolated Extraocular Muscle Involvement as the Ophthalmic Manifestation of Leukaemia. Clinical and Experimental Ophthalmology, 37(6), 609-613. https://doi.org/10.1111/j.1442-9071.2009.02099.x

Kouchkovsky, De., \& Abdul-Hay, M. (2016). Acute myeloid leukaemia: A Comprehensive Review. Journal of Blood Cancer, 6(7), 441. https://doi.org/10.1038/bcj.2016.50

Mangla, D., Dewan, M., \& Meyer, D. R. (2012). Adult Orbital Myeloid Sarcoma (Granulocytic Sarcoma): Two Cases and Review of the Literature. Orbit, 31(6), 438-440. https://doi.org/10.3109/01676830.2012.723784

Max, A. L., Charalampakis, M., Ford, S. J., Gourevitch, D., \& Desai, A. (2017). Myeloid Sarcoma: Presentation, Diagnosis, and Treatment. https://doi.org/10.1016/j.clml.2017.02.027

Menasce, L. P., Banerjee, S. S., Bcekett, E., \& Harris, M. (1999). Extra-medullary Myeloid Tumour (Granulocytic Sarcoma) is Often Misdiagnosed: A Study of 26 Cases. Histopathology, 34(5), 391. https://doi.org/10.1046/j.1365-2559.1999.00651.x

Neiman, R. S., Barcos, M., Berard, C., Bonner, H., Mann, R., Rydell, R. E., \& Bennett, J. M. (1981). Granulocytic Sarcoma: A Clinicopathologic Study of 61 Biopsied Cases. Cancer, 48, 1426. https://doi.org/10.1002/1097-0142(19810915)48:6<1426::AID-CNCR2820480626>3.0.CO;2-G

Ooi, G. C., Chim, C. S., Khong, P. L., Au, W. Y., Lie, A. K., Tsang, K .W., \& Kwong, Y. L. (2001). Radiologic manifestations of Granulocytic Sarcoma in Adult Leukemia. American Journal of Roentgenology, 176(6), 1427-1431. https://doi.org/10.2214/ajr.176.6.1761427

Piled, S. A., Ascani, S., Cox, M. C., Campidelli, C., Bacci, F., Piccioli, M., ... Baccarani, M. (2007). Myeloid Sarcoma: Clinico-Pathologic, Phenotypic and Cytogenetic Analysis of 92 Adult Patients. Leukemia, 21(2), 340-350. https://doi.org/10.1038/sj.leu.2404491

Schachat, A. P. (1989). Ophthalmic Manifestations of Leukemia. Arch Ophthalmol, 107, 697. https://doi.org/10.1001/archopht.1989.01070010715033

Schwyzer, R., Sherman, G. G., Cohn, R. J., Poole, J. E., \& Willem, P. (1998). Granulocytic Sarcoma in Children with Acute Myeloblastic Leukemia and t(8;21). MedPediatrOncol, 31(3), 144-149. https://doi.org/10.1002/(SICI)1096-911X(199809)31:3<144::AID-MPO3>3.0.CO;2-B

Seifert, R. P., Bulkeley, W., Zhang, L., Menes, M., \& Bui, M. M. (2014). A Practical Approach to Diagnose Soft Tissue Myeloid Sarcoma Preceding or Coinciding with Acute Myeloid Leukemia. Ann DiagnPathol, 18(4), 253-60. https://doi.org/10.1016/j.anndiagpath.2014.06.001

Stepensky, P., Revel-Vilk, S., Yehuda-Gafni, O., Mali, B., Resnick, I. B., \& Weintraub, M. (2009). Isolated Central Nervous System Granulocytic Sarcoma and Meningeal Myeloid Leukemia: Successful Treatment without Radiotherapy. The Israel Medical Association Journal, 11(9), 569-570

Wang, H. Q., \& Li, J. (2016). Clinicopathological Features of Myeloid Sarcoma: Report of 39 Cases and Literature Review. Pathol Res Pract., 212(9), 817-824. https://doi.org/10.1016/j.prp.2016.06.014

Vardiman, J. W., Thiele, J., \& Arber, D. A. (2009). The 2008 Revision of the World Health Organization (WHO) Classification of Myeloid Neoplasms and Acute Leukemia: Rationale and Important Changes. Blood, 114(5), 937-951. https://doi.org/10.1182/blood-2009-03-209262 


\section{Copyrights}

Copyright for this article is retained by the author(s), with first publication rights granted to the journal.

This is an open-access article distributed under the terms and conditions of the Creative Commons Attribution license (http://creativecommons.org/licenses/by/4.0/). 